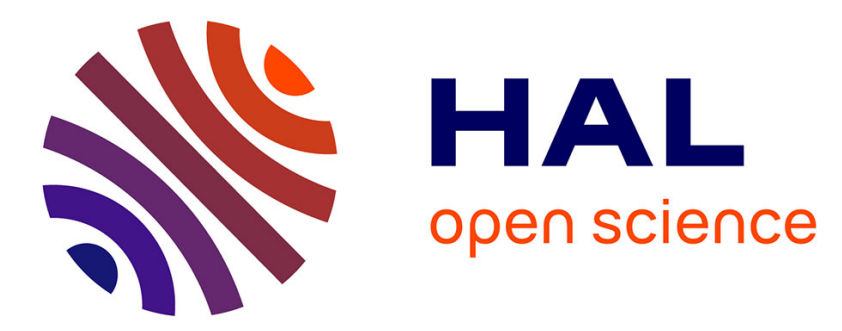

\title{
African horse sickness in The Gambia: circulation of a live-attenuated vaccine-derived strain
}

C.A.L Oura, P.A.S Ivens, K. Bachanek-Bankowska, A. Bin-Tarif, D.B Jallow, Corinne Sailleau, S. Maan, P.C. Mertens, C.A. Batten

\section{- To cite this version:}

C.A.L Oura, P.A.S Ivens, K. Bachanek-Bankowska, A. Bin-Tarif, D.B Jallow, et al.. African horse sickness in The Gambia: circulation of a live-attenuated vaccine-derived strain. Epidemiology and Infection, 2011, 140, pp.462-465. hal-01191108

\author{
HAL Id: hal-01191108 \\ https://hal.science/hal-01191108
}

Submitted on 1 Sep 2015

HAL is a multi-disciplinary open access archive for the deposit and dissemination of scientific research documents, whether they are published or not. The documents may come from teaching and research institutions in France or abroad, or from public or private research centers.
L'archive ouverte pluridisciplinaire HAL, est destinée au dépôt et à la diffusion de documents scientifiques de niveau recherche, publiés ou non, émanant des établissements d'enseignement et de recherche français ou étrangers, des laboratoires publics ou privés. 


\title{
SHORT REPORT
}

\section{African horse sickness in The Gambia: circulation of a live-attenuated vaccine-derived strain}

\author{
C. A. L. OURA ${ }^{1 *}$, P. A. S. IVENS ${ }^{2}$, K. BACHANEK-BANKOWSKA ${ }^{1}$, \\ A. BIN-TARIF ${ }^{1}$, D. B. JALLOW ${ }^{3}$, C. SAILLEAU ${ }^{4}$, S. MAAN ${ }^{1}$, P. C. MERTENS \\ AND C. A. BATTEN ${ }^{1}$ \\ ${ }^{1}$ Institute for Animal Health, Pirbright, Woking, Surrey, UK \\ ${ }^{2}$ Buckingham Equine Medicine Referrals, Overton Fields, Maids Moreton, Buckingham, Bucks, UK \\ ${ }^{3}$ Gambia Livestock Marketing Agency, Abuko, The Gambia \\ ${ }^{4}$ UMR 1161 Virology ANSES/INRA/ENVA, France
}

(Accepted 10 April 2011; first published online 9 May 2011)

\section{SUMMARY}

African horse sickness virus serotype 9 (AHSV-9) has been known for some time to be circulating amongst equids in West Africa without causing any clinical disease in indigenous horse populations. Whether this is due to local breeds of horses being resistant to disease or whether the AHSV-9 strains circulating are avirulent is currently unknown. This study shows that the majority ( $96 \%$ ) of horses and donkeys sampled across The Gambia were seropositive for AHS, despite most being unvaccinated and having no previous history of showing clinical signs of AHS. Most young horses ( $<3$ years) were seropositive with neutralizing antibodies specific to AHSV-9. Eight young equids ( $<3$ years) were positive for AHSV-9 by serotype-specific RT-PCR and live AHSV-9 was isolated from two of these horses. Sequence analysis revealed the presence of an AHSV-9 strain showing $100 \%$ identity to Seg- 2 of the AHSV-9 reference strain, indicating that the virus circulating in The Gambia was highly likely to have been derived from a live-attenuated AHSV-9 vaccine strain.

Key words: Animal pathogens, asymptomatic viral infections, immunization (vaccination), veterinary epidemiology, veterinary virology.

African horse sickness virus (AHSV), a doublestranded RNA orbivirus belonging to the family Reoviridae, causes a non-contagious arthropod-borne disease of equidae. The virus is widely distributed across sub-Saharan Africa where it is transmitted between susceptible vertebrate hosts by Culicoides biting midges, and also possibly by mosquitoes and ticks [1]. The Sahara desert seems to act as a geographical

\footnotetext{
* Author for correspondence: Dr C. A. L. Oura, Institute for Animal Health, Ash Road, Pirbright, Woking, Surrey, GU24 0NF, UK.

(Email: chris.oura@bbsrc.ac.uk)
}

barrier to the spread to the virus out of Africa. That said, AHSV serotype 9 (AHSV-9) was responsible for a devastating epizootic in the Middle East and Southwest Asia in 1959 and 1960 which caused the death of around 300000 horses during the first phase of infection [2]. In the course of this epidemic the ratio of mortality to inapparent infection varied considerably [3] which left many questions unanswered about the factors affecting the pathogenicity of this serotype. In 1965 AHSV-9 again spread beyond its traditional enzootic zones in sub-Saharan Africa into Morocco, Algeria and Tunisia and then into Southern Spain in 1966 [4]. 
AHSV-9 has been known for some time to be circulating in the West African equidae population without causing significant clinical disease in the local indigenous horse populations. AHSV-9 was isolated for the first time in Nigeria in 1970 from a horse that died with typical clinical signs of AHS [5]. In a small serological survey carried out in Nigeria, $60 \%$ of the horses sampled were found to have neutralizing antibodies to AHSV-9 [6] and no previous vaccination had been carried out in the region. In 1974 about 20 horses that had recently been imported into Nigeria died showing clinical signs of AHS and interestingly at no time during the outbreak were any locally bred horses reported to be ill. An emulsion of spleen tissue from one of the dead horses was injected into a locally bred horse previously shown to have no neutralizing antibodies to AHSV and this animal showed only mild clinical signs followed by complete recovery. This result indicated that local breeds of horses in Nigeria may show a high degree of resistance to infection with AHSV; however, imported 'exotic' breeds appear to be highly susceptible.

Several studies investigating the prevalence of AHS in horses in Senegal and The Gambia have previously been conducted. Mattioli et al. [7] tested sera from 112 donkeys and 15 horses in The Gambia for AHS antibodies and found $95.5 \%$ of the donkeys and all the horses to be seropositive for AHSV-9. They concluded that these high titres suggested a recent and continuous contact with AHSV-9, although interestingly, with the exception of one suspected but not confirmed case, no clinically sick animals were recorded. Similar high levels of seroprevalence to AHSV-9 were also recorded in horses and donkeys in Senegal $[8,9]$ which is not surprising as both The Gambia and Senegal are within the same region in which AHS is considered to be endemic. In a separate study conducted in The Gambia by Staeuber et al. [10], $81 \%$ of the 459 horse serum samples collected tested seropositive for AHSV antibodies. The high percentage of AHSV antibodypositive horses in The Gambia along with a lack of clinical signs suggest that either the local breeds of horses may be resistant to AHS or alternatively the AHSVs circulating may not be virulent. Culicoides spp. that are known to transmit or are suspected vectors of AHSV are abundant in The Gambia [11].

We set out to try to address the question of whether the high levels of seroconversion seen in The Gambia were due to an increased resistance of horses living in the region to AHS or whether the AHSV circulating in the region was less virulent and possibly derived from the live-attenuated vaccine, which had been used in the region for many years. In response to a suspected AHS outbreak in The Gambia and Senegal during September 2007, a vaccination campaign using a monovalent live-attenuated AHSV-9 vaccine from Senegal or a polyvalent live-attenuated vaccine from South Africa (containing serotypes 1, 2, 3, 4, 6, 7, 8) was administered in 2007 to horses in The Gambia. In October 2009 a serological and virological survey for AHS was undertaken. In total 144 equids (horses and donkeys) were sampled from seven villages in the north Nianija district in mid Gambia, where clinical signs consistent with AHS had been recognized in some horses during 2007 (group 1), and 10 villages south of the river Gambia in the district of Niamina, where AHS clinical signs had not previously been reported (group 2). The clinical and vaccination history of each equid was recorded. The median age of the equids (101 horses, 43 donkeys) was 7 years (range 1-20 years). Out of 122 equids from group 1, sampled north of the river Gambia, 21 (17\%) were vaccinated as part of the campaign in 2007. None of the 22 equids sampled from south of the river Gambia were vaccinated.

The majority of horses from both groups $(96 \%)$ were seropositive for AHS antibodies as determined by ELISA (Ingenasa, Spain), despite most being unvaccinated and having no previous history of showing clinical signs of AHS. Five out of 144 equids that tested seronegative were all horses that were aged $\leqslant 3$ years. The majority of equids (horses and donkeys) were seropositive for AHS antibodies from an early age ( $>2$ years). Serum neutralization tests (SNTs) against all nine serotypes of AHSV showed that, in a selection of 15 younger equids that were unvaccinated and antibody-ELISA positive, all had neutralizing antibodies specific to AHSV-9 (Table 1). This indicated that AHSV-9 is likely to be the only serotype that is circulating in the region.

Eight young equids ( 6 horses, 2 donkeys) that were all aged $<3$ years tested positive for AHSV RNA by real-time RT-PCR assay [12] giving cycle threshold $\left(C_{t}\right)$ values of between 29 and 41. Live AHSV (dsRNA reference collection GAM2009/01 and GAM2009/02) was isolated on $\mathrm{KC}$ (Culicoides variipennis) cells from two of these samples with the lowest $C_{t}$ values (29.5 and 30.5) indicating that AHSV was circulating freely in the region and was being transmitted by the local midge population (Culicoides spp.). Of the eight samples that were PCR positive, seven were also antibody positive in ELISA; however, the remaining 
Table 1. Serological (ELISA/serum neutralization test) and virological (real-time RT-PCR) responses in young unvaccinated horses in The Gambia

\begin{tabular}{|c|c|c|c|c|c|c|c|c|c|c|c|c|}
\hline \multirow{2}{*}{$\begin{array}{l}\text { Horse } \\
\text { (ID) }\end{array}$} & \multirow{2}{*}{$\begin{array}{l}\text { Age } \\
(\mathrm{yr})\end{array}$} & \multirow{2}{*}{$\begin{array}{l}\text { PCR } \\
\left(C_{t}\right)\end{array}$} & \multirow[b]{2}{*}{ ELISA } & \multicolumn{9}{|c|}{ Serum neutralization titres $\left(\log _{10}\right)$} \\
\hline & & & & AHS-1 & AHS-2 & AHS-3 & AHS-4 & AHS-5 & AHS-6 & AHS-7 & AHS-8 & AHS-9 \\
\hline 9 & 2 & n.d. & + & Neg & Neg & Neg & Neg & Neg & Neg & Neg & Neg & $2 \cdot 68$ \\
\hline 21 & 2 & n.d. & + & Neg & Neg & Neg & Neg & Neg & $\mathrm{Neg}$ & Neg & Neg & $2 \cdot 08$ \\
\hline 30 & 2 & n.d. & + & $\mathrm{Neg}$ & Neg & Neg & $\mathrm{Neg}$ & $\mathrm{Neg}$ & $\mathrm{Neg}$ & Neg & $\mathrm{Neg}$ & $2 \cdot 20$ \\
\hline 37 & 2. & n.d. & + & $\mathrm{Neg}$ & Neg & Neg & $\mathrm{Neg}$ & $\mathrm{Neg}$ & $\mathrm{Neg}$ & Neg & 1 & $1 \cdot 78$ \\
\hline 70 & 2 & n.d. & + & $\mathrm{Neg}$ & Neg & Neg & Neg & Neg & $\mathrm{Neg}$ & Neg & Neg & $2 \cdot 20$ \\
\hline 83 & 3 & n.d. & + & Neg & Neg & Neg & Neg & Neg & $\mathrm{Neg}$ & Neg & Neg & $2 \cdot 68$ \\
\hline 98 & 4 & n.d. & + & $\mathrm{Neg}$ & Neg & Neg & $\mathrm{Neg}$ & $\mathrm{Neg}$ & $\mathrm{Neg}$ & Neg & Neg & 1.90 \\
\hline 102 & 4 & n.d. & + & $\mathrm{Neg}$ & Neg & $\mathrm{Neg}$ & Neg & $\mathrm{Neg}$ & $\mathrm{Neg}$ & $\mathrm{Neg}$ & $\mathrm{Neg}$ & $1 \cdot 48$ \\
\hline 111 & 2 & n.d. & + & $\mathrm{Neg}$ & Neg & Neg & $\mathrm{Neg}$ & $\mathrm{Neg}$ & $\mathrm{Neg}$ & Neg & Neg & $2 \cdot 08$ \\
\hline 114 & 2 & n.d. & + & $\mathrm{Neg}$ & Neg & Neg & Neg & $\mathrm{Neg}$ & $\mathrm{Neg}$ & Neg & Neg & $3 \cdot 11$ \\
\hline 136 & 2 & n.d. & + & Neg & Neg & $1 \cdot 48$ & Neg & Neg & $1 \cdot 30$ & $1 \cdot 48$ & 1 & $>3 \cdot 11$ \\
\hline 46 & 2 & n.d. & + & $\mathrm{Neg}$ & Neg & Neg & $\mathrm{Neg}$ & $\mathrm{Neg}$ & Neg & Neg & Neg & $1 \cdot 78$ \\
\hline 60 & 2 & n.d. & + & $\mathrm{Neg}$ & Neg & Neg & Neg & Neg & $\mathrm{Neg}$ & Neg & Neg & $2 \cdot 81$ \\
\hline 108 & 3 & n.d. & + & $\mathrm{Neg}$ & $\mathrm{Neg}$ & $\mathrm{Neg}$ & Neg & Neg & $\mathrm{Neg}$ & $\mathrm{Neg}$ & 1 & $2 \cdot 68$ \\
\hline 113 & 3 & n.d. & + & $\mathrm{Neg}$ & Neg & Neg & Neg & Neg & $\mathrm{Neg}$ & 1 & Neg & $2 \cdot 38$ \\
\hline 6 & 2 & n.d. & - & $\mathrm{Neg}$ & Neg & Neg & $\mathrm{Neg}$ & Neg & $\mathrm{Neg}$ & Neg & Neg & $\mathrm{Neg}$ \\
\hline 10 & 2 & $+\left(\mathrm{C}_{\mathrm{t}} 37\right)$ & - & Neg & Neg & Neg & Neg & Neg & $\mathrm{Neg}$ & Neg & Neg & Neg \\
\hline
\end{tabular}

n.d., No virus detected; $\mathrm{C}_{\mathrm{t}}$, cycle threshold.

PCR-positive sample, which was taken from a 2-yearold horse, was antibody negative (horse ID no. 10, Table 1), indicating that this animal was likely to be in the early phase of infection before antibodies had developed.

Serotype-specific RT-PCR assays [13] targeting genome segment 2 (Seg-2 - the VP2 gene) identified AHSV serotype 9 in the two samples from which AHSV was isolated. Sequence analysis of Seg-2 confirmed the presence of AHSV-9, and the Seg-2 consensus sequence from both isolates was $100 \%$ identical over a 1653-bp region (615-2268 bp) to Seg-2 from the South African AHSV-9 reference strain (PAKrrah/09). As the AHSV-9 live-attenuated vaccine strain used in previous vaccination campaigns in the region is highly likely to have been derived from the AHSV-9 reference strain, we can therefore conclude that the AHSV-9 live-attenuated vaccine strain is likely to be circulating and infecting equids from an early age in The Gambia. Interestingly, the oral susceptibility of livestock-associated Culicoides spp. to strains of AHSV has been demonstrated to be higher for vaccine as opposed to field strains of AHSV $[14,15]$. Sequence analysis (Seg-2) was also carried out on an AHSV-9 strain isolated from an imported unvaccinated horse from Senegal in 1992 that succumbed to fatal clinical signs of AHS immediately after entry into the country [16]. This revealed a
97.2\% identity over 1653 bp to the ASHV-9 reference strain (PAKrrah/09) and the identical strain circulating in The Gambia, indicating that this Senegal isolate was not derived from the AHSV-9 reference/vaccine strain and was likely to be a field strain.

There are three principal explanations as to why horses within the region, despite being infected with AHSV-9, are not showing any overt clinical signs of disease. The first is that a state of 'endemic stability' to AHSV-9 exists within the region with protective colostral antibodies to AHSV-9 being passed from dams to their offspring. The young equids are then infected with AHSV-9 from an early age, when they are still partially or completely protected by colostral antibodies, and therefore gain lifelong immunity without showing any clinical disease. The second explanation is that indigenous horses within the region are naturally resistant to AHS having 'lived' with the virus for many years. Previous evidence from Nigeria [6] indicates that this may be the case. The third explanation is that the AHSV-9 strain(s) circulating in the region are not virulent and may be derived from tissue-culture-attenuated live vaccine strains used in the region. Sequence analysis presented in this paper indicates that the third explanation is likely to be occurring in The Gambia and that the AHSV-9 strain circulating is likely to have been derived from the liveattenuated AHSV-9 vaccine strain used extensively in 
the region for many decades. This does not, however, preclude the possibility that indigenous horses in the region may also show some degree of resistance to AHS. In order to further address these questions it would be necessary to perform detailed experimental infection studies with local and exotic breeds of horses infected with different AHSV serotypes/strains.

We can conclude that AHSV-9 is endemic in equidae in The Gambia with horses and donkeys in the region being infected with the virus from a young age. It is likely that AHSV-9 is being naturally transmitted by Culicoides midges in the region and there is no evidence that any of the other nine AHSV serotypes are circulating. We can conclude that one reason why many horses in The Gambia are not showing clinical signs of AHS, despite being infected, is that an attenuated vaccine strain is freely circulating within the region. This circulating AHSV-9 vaccine strain is likely to be 'immunizing' equids from an early age and protecting them from infection with more virulent field strains of the same serotype. Although this may have some beneficial effects, provided that the circulating vaccine-derived strain does not revert to virulence, there is clearly potential for genome segment reassortment with field strains that could cause reversion.

\section{ACKNOWLEDGEMENTS}

We thank the Department of Veterinary Services, The Gambia, and in particular Mr Borrie Jabang, Laboratory Technician at the Central Veterinary Laboratory, Abuko. We thank the entire local staff of The Gambia Horse and Donkey Trust, Sambel Kunda, and animal owners for providing their animals for sampling. We also thank the BEVA Trust for funding the field work in The Gambia.

\section{DECLARATION OF INTEREST}

None.

\section{REFERENCES}

1. Mellor PS. Culicoides-do vectors respect national boundaries. British Veterinary Journal 1993; 149: 5-8.

2. Howell PG. Emerging diseases of animals II. African horse sickness. FAO Agricultural Studies 1963; 61: 71-108.
3. Shah KV, Pavri KM. African horse sickness in India. Bulletin of the National Institute of Sciences of India 1963; 24: 194-204.

4. Diaz Montilla R, Panos Marti P. African horse sickness. Bulletin de l'Office International des Epizooties 1968; 70 : 647-662.

5. Kemp GE, Humburg JM, Alhaji I. Isolation and identification of African horse sickness virus in Nigeria. Veterinary Record 1971; 89: 127-128.

6. Kemp GE. Antibody in Nigerian animals to African horse sickness serotype-9. Veterinary Record 1974; 95: 345 .

7. Mattioli RC, Zinsstag J, Pfister K. African horse sickness and equine infectious Anemia serology in The Gambia. Tropical Animal Health and Production 1992; 24: 207-208.

8. Sarr J, Diop M, Cissokho S. African horse sickness in Senegal: the state of natural and/or acquired immunity in horses in a recent foci. Revue d'Elevage et de Medecine Veterinaire des Pays Tropicaux (Paris) 1988; 41: 243-246.

9. Bourdin P. African horse sickness in Senegal: serological tests and vaccination. In: Bryans JT, Gerber H, eds. Equine Infectious Diseases, 4th International Conference on Equine Infectious Diseases. New Jersey: Veterinary Publications, 1978, pp. 405-407.

10. Staeuber N, et al. Seroepidemiological study of African horse sickness virus in The Gambia. Journal of Clinical Microbiology 1993; 31: 2241-2243.

11. Rawlings $\mathbf{P}$, et al. Culicoides in relation to transmission of African horse sickness virus in The Gambia. Medical and Veterinary Entomology 1998; 12: 155-159.

12. Fernandez-Pinero J, et al. Rapid and sensitive detection of African horse sickness virus by real-time PCR. Research in Veterinary Science 2009; 86: 353-358.

13. Sailleau C, et al. Identification and differentiation of the nine African horse sickness virus serotypes by RT-PCR amplification of the serotype-specific genome segment 2. Journal of General Virology 2000; 81: 831837.

14. Paweska JT, Prinsloo S, Venter GJ. Oral susceptibility of South African Culicoides species to live-attenuated serotype-specific vaccine strains of African horse sickness virus (AHSV). Medical and Veterinary Entomology $2003 ; 17: 436-447$.

15. Venter GJ, Paweska JT. Virus recovery rates for wildtype and live-attenuated vaccine strains of African horse sickness virus serotype 7 in orally infected South African Culicoides species. Medical and Veterinary Entomology 2007; 21 : 377-383.

16. Sailleau C, et al. African horse sickness in Senegal: serotype identification and nucleotide sequence determination of segment S10 by RT-PCR. Veterinary Record 2000; 146: 107-108. 